\title{
A system of canals in semilunar menisci
}

\author{
M D T BIRD AND M B E SWEET
}

From the Bone and Joint Research Unit of the South African Medical Research Council and the University of the Witwatersrand, Johannesburg, South Africa

SUMmARY Semilunar menisci of young calves, and infants and young children were examined with the scanning electron microscope and the light microscope. Canal-like structures were noted opening onto the surface of the menisci. After filling the joints with Indian ink, ink was notec within canal-like structures deep in the substance of the tissue. The canals may play a part in the transport of fluid within the meniscus, or may carry nutrients from the synovial fluid or the bloot vessels to the avascular sections of the meniscus.

The semilunar menisci are fibrocartilaginous structures, which play an important part in the function of the knee: they stabilise the joint and transmit load from the femur to the tibia. They are thought to facilitate lubrication. ${ }^{2}$ It is known that developing menisci are different from those of adolescents and adults: they contain more vessels, are much more cellular, and may have greater reparative properties."

A number of workers have studied the surface of menisci using the scanning electron microscope: the femoral and tibial surfaces are similar and show ridges and grooves running predominantly in the long axis of the tissue. ${ }^{+5}$ which may be due to shrinkage." Humps have been observed on the surface of the menisci of children. ${ }^{67}$

In this study we have used the scanning electron microscope and the light microscope to examine the surface of menisci of young children and new born calves. We present evidence for the existence of a system of canaliculi linking the surface with the depths of the tissue.

\section{Materials and methods}

Human knee joints were obtained from two stillborn individuals and after death from subjects aged 3 weeks, 1 year, 3 years, and 6 years. After examination of some of the specimens the possibility of postmortem artefactual changes was considered. Consequently, knee joints of six near term fetal

Accepted for publication 31 March 1987.

Correspondence to Dr M B E Sweet. Department of Orthopacdic Surgery, Medical School, York Road. Parktown 2193. South Africa. calves and of six three month old calves obtainec $\$$ from the abattoir immediately after slaughter were studied in parallel.

Freshly dissected menisci were fixed in $2 \%$ paraformaldehyde in $0.2 \mathrm{M}$ phosphate buffer. $\mathrm{pI}$ $7 \cdot 3$, for 48 hours. After stepwise dehydrationg alcohol the specimens were placed in a critical pots dryer, affixed to aluminium stubs, and coated gold. Specimens were viewed in a JOEL ?5 scanning electron microscope.

The joint capsule was kept intact, and the kneog joints of three calves and two infants were infuse with Indian ink. The joints were extensively flexef and compressed for an hour. Thereafter the menis $\bar{\Phi}$ were excised. fixed. and embedded in wax. Section? of $7 \mu \mathrm{m}$ were stained with haematoxylin and eosin o alcian blue and nuclear fast red. Some specimens were embedded in methacrylate and cut on a Jung $\frac{0}{\delta}$ microtome.

\section{Results}

The results presented refer to the superior ang inferior surfaces of the semilunar menisci take from both the medial and lateral side.

The calf menisci were about as large as adult human menisci but were about twice as thick on the attached edge. The surface was smooth and glistert ing when viewed with the naked eye or through th: dissecting microscope at a magnification of $20 \times 0$ The inner free edge was intact. Regular concentribs ridges were visible on both superior and inferiof surfaces.

With the scanning electron microscope larget roughly oval shaped apertures were visible at 


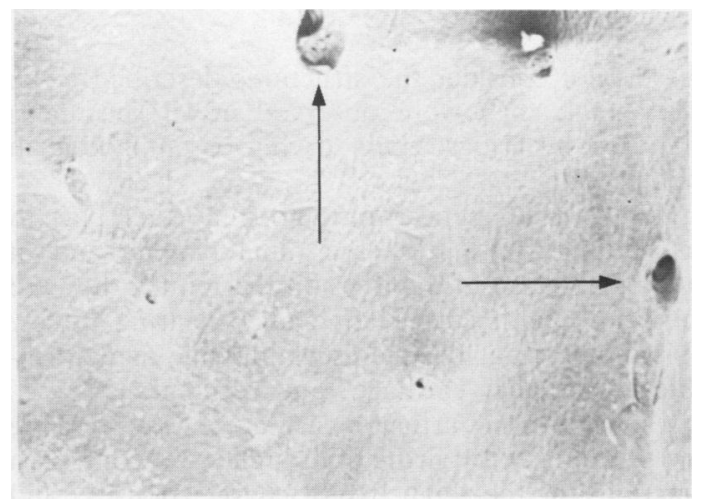

Fig. 1 Surface of meniscus from three month old calf showing large crater-like openings.

magnification of $45 \times$ (Fig. 1). At higher magnification $(300 \times)$ the apertures appeared to resemble shafts, into the depths of which opened further apertures (Fig. 2). The narrowest diameter of these structures was approximately $200 \mu \mathrm{m}$. These structures were surrounded by large numbers of smaller apparent holes with a definite limbus (15-20 $\mu \mathrm{m}$ in diameter), giving the plateau a porous appearance (Fig. 2). There was no significant difference between the menisci of the fetal and the three month old animals.

Examination of infant human material did not show any apertures resembling the large openings of $200 \mu \mathrm{m}$ diameter. The general appearance of the surface of the menisci was as described by others." At higher magnification $(2000 \times)$, however, small

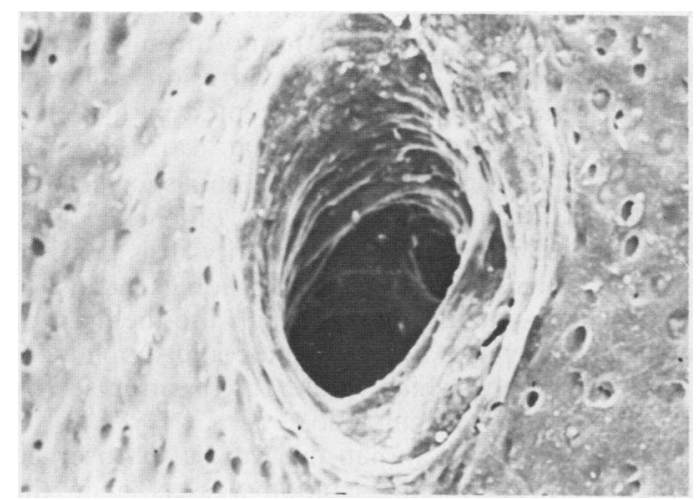

Fig. 2 Surface of meniscus from calf showing detail of opening with further openings in its depths. Smaller openings are shown on the surrounding surface.

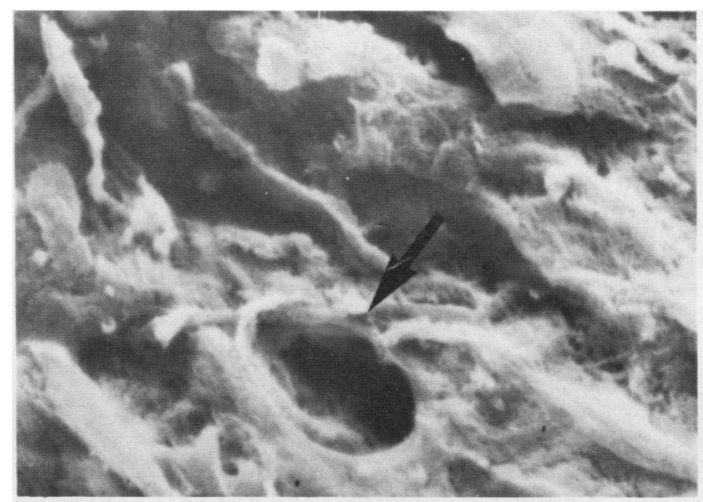

Fig. 3 Surface of meniscus from new born infant showing a defined opening.

openings of between 10 and $60 \mu \mathrm{m}$ diameter were clearly visible (Fig. 3). These were structurally similar to those seen in the calf menisci, but more sparsely distributed. The structures were seen at all ages studied.

Calf menisci were examined in the light microscope both with and without Indian ink treatment. In a cross section canal-like structures were clearly visible between cross cut collagen bundles (Fig. 4). The structures had definite but acellular walls. They were distinguished from blood vessels as they had no muscular wall and no adventitia. Furthermore, many were of larger diameter than adjacent blood vessels. Indian ink was found to be present within the lumen of some of the canals (Fig. 5).

When the human menisci were examined in the

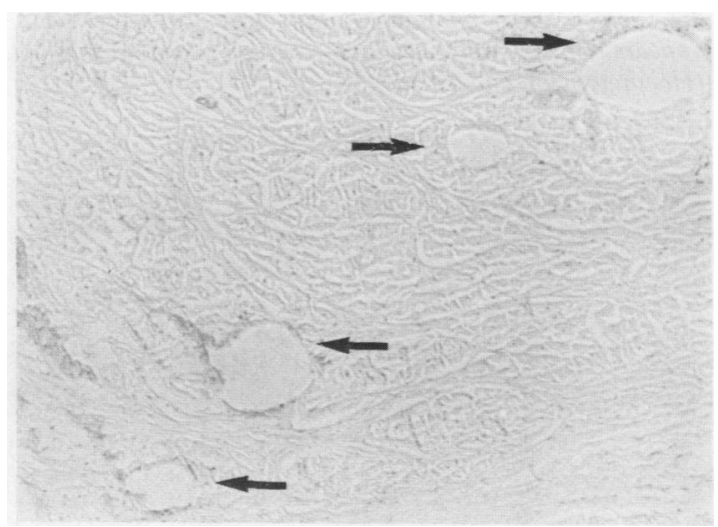

Fig. 4 Histological section of calf meniscus showing canals in a cross section. (Haematoxylin and eosin.) 
light microscope it was appreciated that the canals would be of a very much smaller size than in the calf. Nonetheless, we did see canals opening onto the surface, which were filled with Indian ink (Fig. 6). In addition, Indian ink was noted in canals or loosely packed tissue deep within the meniscus, some of which surrounded blood vessels near the attached edge (Fig. 7).

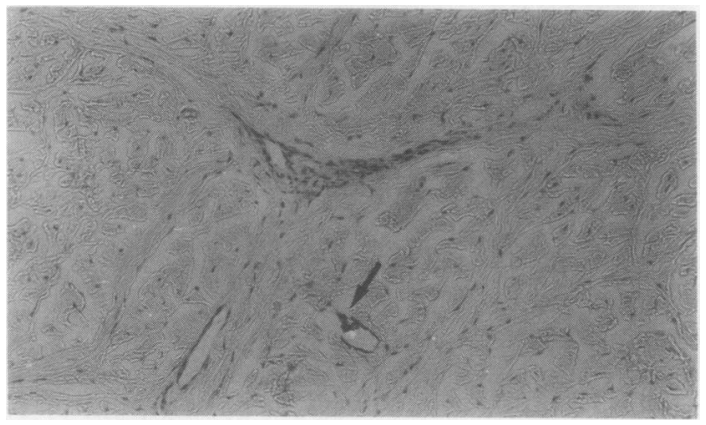

Fig. 5 Calf menicus showing canal containing Indian ink, adjacent to blood vessels. (Haematoxylin and eosin.)

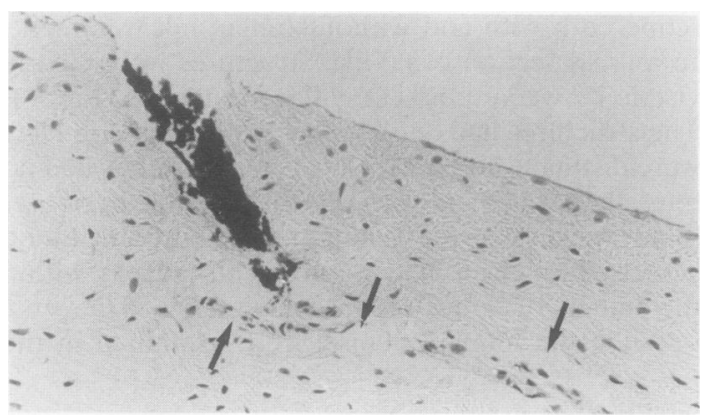

Fig. 6 Human meniscus showing canal opening onto the surface and containing Indian ink. The canal appears to be continuous with a reticular system as marked. (Haematoxylin and eosin.)

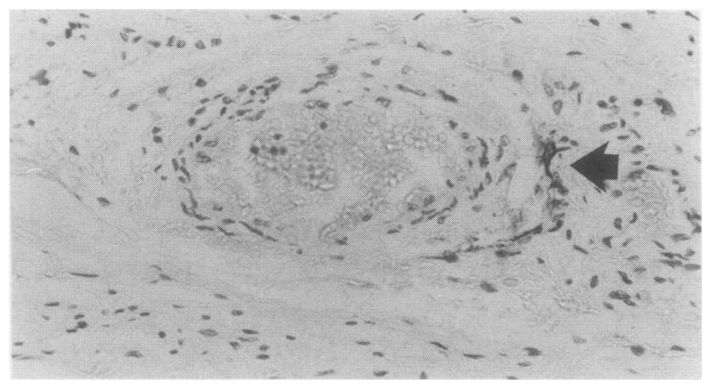

Fig. 7 Human mensicus showing arteriole close to the attached edge. The marker indicates Indian ink present within loosely packed tissue surrounding the vessel.

\section{Discussion}

We do not consider the structures described to artefactual: they were observed in all specimenes prepared by critical point drying or embedded methacrylate.

Because the menisci play an important part i i distributing stress over the tibial plateau and i⿺ guiding rotation of the tibia on the femur, they arg subject to both compressive and shearing forces This implies that the meniscus must be as deform: able as articular cartilage, and resilient.

It is known that articular cartilage is compressible and deformable by virtue of its high water content, $\frac{\mathscr{W}}{\delta}$ function of the high fixed charge density and

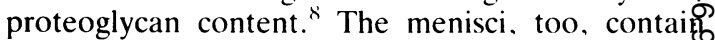
proteoglycans, which are in many respects similar to those found in articular cartilage." 11 "The wated content of meniscus is about $68 \%$ in adults and $80 \%$ in infants (Bird and Sweet, unpublished data); a proportion of this is presumably held by the osmoti\& pressure generated by the ions and counterions surrounding the anionic proteoglycans. The syster of canals we have described may play a part ig permitting the rapid flow of water from one section of the meniscus to another during weight beariogg $\overrightarrow{0}$

The surface openings of the canals seen in the specimens were very much larger than those seepip human material. The menisci themselves w.ero virtually the size of adult human menisci. Whateve the function of the canals, it seems likely that thio functional demands of walking immediately afteo birth may call for greater efficiency of the system in the calf. At present it is not known whether such $\Phi$ system persists into adulthood.

In man there is a well developed vascular supp to the menisci: a perimeniscal circular vascular ringi supplies the peripheral attached region and send radial branches into the substance of the menisci. $\frac{9}{0}$ In the fetus vessels are to be found throughout the meniscus. ${ }^{3}$ We are aware that diffusion from the synovial fluid is a commonly accepted pathway fo nutrients entering both articular cartilage and meniscus. The Indian ink experiments showed that the canals within the substance of the menises communicate with the synovial cavity. It is possible that the canals provide an additional means of transporting synovial fluid through the menisci foro nutritional purposes. This system could supplemento a vascular supply, which would be compromised by the pressure of normal load.

Canals containing Indian ink were also observef immediately surrounding blood vessels near thळ attached edge of the infant menicus. This, on the other hand, suggests the possibility of the canats transporting a nutrient transudate of serum from 
this region of the meniscus through the tissue and out into the synovial fluid.

This work was supported by the South African Medical Research Council, the Orthopaedic Research Foundation, and the Slome Orthopaedic Trust Fund. The authors thank Professor A Davies. Mr G van Sittert, and Mrs G Brunton of the National Council for Occupational Health for assistance with scanning electron microscopy.

\section{References}

1 Shrive N, O'Connor J J, Goodfellow J W. Load-bearing in the knee joint. Clin Orthop 1974; 131: 279-87.

2 Duthie R B, Bentley G. Mercer's orthopaedic surgery. London: Arnold, 1983: 977-8.

3 Clark C R, Ogden J A. Development of the menisci of the human knee joint. J Bone Joint Surg [Am] 1983; 65A: 536-47.

4 Cameron H U, MacNab I. The structure of the meniscus of the human knee joint. Clin Orthop 1972; 89: 215-9.

5 Cameron H U, MacNab I. Lesions of the menisci in man: a scanning electron microscope study. Scan Electron Microsc 1973: $667-74$.

6 Ghadially F N. Fine structure of joints. In: Sokoloff L. cd. The joints and synovial fluid. New York: Academic Press. 1978: 105-76.

7 Refior H J. Altersabhangige Veranderungen der Meniscusoberflache Untersuchungen mit dem Rasterelektronenmikroskop. Archiv fur Orthopadische und Unfallchirurgie 1971: 71: 316-23.

8 Bayliss M T, Venn M. Chemistry of human articular cartilage. In: Maroudas A, Holborow E J, eds. Studies in joint disease I. Tunbridge Wells: Pitman Medical, 1980: 2-58.

9 Roughley P J, McNicol D, Santer V. Buckwalter J. The presence of a cartilage-like proteoglycan in the adult human meniscus. Biochem J 1981; 197: 77-83.

10 Webber R J. Norby D P, Malemud C J, Goldberg V M, Moskowitz $\mathrm{R} \mathrm{W}$. Characterization of newly synthesized proteoglycans from rabbit menisci in organ culture. Biochem $J$ 1984; 221: 875-84.

11 Arnoczy S P, Warren R F. Microvasculature of the human meniscus. Am J Sports Med 1982; 10: 90-5. 